\title{
Environmental sustainability assessment of seawater reverse osmosis brine valorization by means of electrodialysis with bipolar membranes
}

Marta Herrero-Gonzalez ${ }^{a}$, Noy Admon ${ }^{b}$, Antonio Dominguez-Ramos ${ }^{a}$, Raquel Ibañez $^{a}$, Adi Wolfson $^{b}$, Angel Irabien ${ }^{a}$

a Departamento de Ingenierías Química y Biomolecular, Universidad de Cantabria, Avenida de los Castros s/n, 39005 Santander, Cantabria, Spain

${ }^{\mathrm{b}}$ Green Processes Center, Sami Shamoon College of Engineering, 56 Bialik St., 84100, Beer-Sheva, Israel

\author{
* Corresponding author \\ E-mail: herrerogma@unican.es \\ Telephone: +34942202052
}

Keywords (6-8)

Sustainability; desalination; brines; carbon footprint (CF); electrodialysis with bipolar membranes (EDBM); seawater reverse osmosis (SWRO)

\begin{abstract}
(10-15 lines)
The integration of electrodialysis with bipolar membranes (EDBM) with seawater reverse osmosis (SWRO) process influences the two main environmental burdens of SWRO desalination process: climate change, associated to the high-energy consumption, and the environmental alteration of the vicinities of the facility, due to brine disposal. EDBM powered by photovoltaic (PV) solar energy is able to meet the abovementioned challenges that arise in SWRO desalination. In addition, $\mathrm{HCl}$ and $\mathrm{NaOH}$, both employed in desalination industry, can be produced from the brines. Hence, environmental benefits regarding the potential self-supply can be achieved.
\end{abstract}

The environmental sustainability assessment by means of Life Cycle Assessment (LCA) of a SWRO and EDBM has been carried out considering four different scenarios. The percentage of treated brines and the influence of the grid mix used for electric power supply has been taken into account. The three different electric power supplies were: 100.0\% renewable energy (PV solar energy), 36.0\% renewable energy 
(average Spanish grid mix) and 1.9\% (average Israeli grid mix). The results showed that the CF per unit of volume produced freshwater for SWRO and the self-supply reagent production scenario for the three Spanish grid mix, the Israeli grid mix and the PV solar energy were: $6.96 \mathrm{~kg} \mathrm{CO}$-eq $\mathrm{m}^{-3}, 12.57 \mathrm{~kg} \mathrm{CO}_{2}$ $\mathrm{eq} \cdot \mathrm{m}^{-3}$, and $2.17 \mathrm{~kg} \mathrm{CO}$-eq $\cdot \mathrm{m}^{-3}$, respectively. In that particular scenario, even if PV solar energy is chosen for the electrons supply, the figures shows a high contribution of the concentration of products stage to the total electric energy consumption.

\section{Introduction}

Desalination technologies have been developed to meet the increasing global demand of freshwater being the projected desalination capacity of 54 billion $\mathrm{m}^{3} \cdot \mathrm{year}^{-1}$ for 2030 (Shahzad et al. 2017). In this

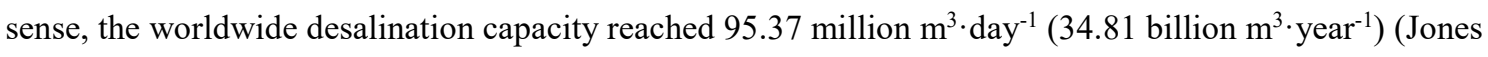
et al. 2019). Seawater reverse osmosis (SWRO) is the most economical technology compared to different commercial scale desalination technologies (Drioli et al. 2017) dominating the desalination market with a share of $65 \%$ of the installed capacities (Amy et al. 2017).

Although SWRO is a suitable and well-established commercial alternative for desalination, some drawbacks can be pointed out, such as: i) brine disposal (waste effluent) into the water bodies, and ii) the indirect greenhouse gas (GHG) emissions associated to the high energy consumption (Palomar and Losada 2011; Tarnacki et al. 2012).

Highly-hypersaline streams, the so called brines, are generated, approximately in the same amount as freshwater (Meneses et al. 2010), during the SWRO desalination process (Pérez-González et al. 2012). Concentration of salts in brines vary from $44.0 \mathrm{~g} \cdot \mathrm{L}^{-1}$ to $75.2 \mathrm{~g} \cdot \mathrm{L}^{-1}$ (García-Rubio and Guardiola 2012), which means that brines are twice concentrated than seawater. In addition, brine also contains small amounts of various chemicals that were employed in the pre-treatment and cleaning stages of the process. Typically, brines are discharged directly into the seawater bodies because other proposed alternatives are far from being technically, socially, economically or environmentally feasible (Palomar and Losada 2011). Nevertheless, several studies have analyzed the effects of brine disposal into the marine ecosystems (Fernández-Torquemada and Sánchez-Lizaso 2005; Gacia et al. 2007; Del-Pilar-Ruso et al. 2008; SánchezLizaso et al. 2008; Roberts et al. 2010; Yoon and Park 2011; Belkin et al. 2015, 2017; de-la-Ossa-Carretero et al. 2016; Fernandez-Gonzalez et al. 2016; Röthig et al. 2016). These studies concluded that the desired disposal concentrations are below the typical brine concentration, and this fact leads to two approaches: i) a disposal on empty areas of vegetation (Einav et al. 2003), or ii) a treatment of the brines in order to reduce the concentrations and/or their valorization (Jiang et al. 2014a, b; Ortiz-Albo et al. 2019). Electrodialysis with bipolar membranes (EDBM) has been proved a suitable and emerging technology for treatment and valorization of SWRO brines (Koter and Warszawski 2006; Pérez-González et al. 2012; Wang et al. 2014; Yang et al. 2014; Fernandez-Gonzalez et al. 2016; Reig et al. 2016). 
EDBM is a promising technology that gained attention over the last years due to its application in treatment and valorization of desalination brines. $\mathrm{HCl}$ and $\mathrm{NaOH}$ can be produced by means of EDBM from two inputs: brine (mostly composed by $\mathrm{NaCl}$ and water) and energy. Both $\mathrm{HCl}$ and $\mathrm{NaOH}$ are commodities employed in a wide range of industries, including desalination industry itself. These chemicals are required in the pre-treatment ( $\mathrm{pH}$ adjustments), cleaning and maintenance stages, consuming between $15 \mathrm{mg} \cdot \mathrm{L}^{-1}$ and $100 \mathrm{mg} \cdot \mathrm{L}^{-1}$ of $\mathrm{H}_{2} \mathrm{SO}_{4}$ (Fernandez-Gonzalez et al. 2016). $\mathrm{As}_{2} \mathrm{SO}_{4}$ can increase the sulphate scaling potential (Tate 2008; Ras and von Blottnitz 2012), it can be replaced with a range between $11 \mathrm{mg} \cdot \mathrm{L}^{-}$ ${ }^{1}$ and $73 \mathrm{mg} \cdot \mathrm{L}^{-1}$ of $\mathrm{HCl}$ (Fernandez-Gonzalez et al. 2016). In addition, transportation and storage of large quantities of acid can trigger safety problems, along with environmental burdens such as $\mathrm{CO}_{2}$ emission during transportation. Hence, economic benefits regarding the potential self-supply can be achieved.

Both SWRO and EDBM are intrinsically high intensive energy consumer technologies (Kalogirou 2001), which deals into indirect effects over environment by the release of different air pollutants from conventional energy production stages, such as $\mathrm{CO}_{2}, \mathrm{NO}_{\mathrm{X}}$ and $\mathrm{CH}_{4}$, which are responsible of the greenhouse effect. Estimations claim that 76 million of tones of $\mathrm{CO}_{2}$ where emitted worldwide due to desalination plants in 2015 (Masdar 2015). Yet, coupling SWRO process to renewable energy sources can reduce the GHG emission up to $90 \%$ (Shahabi et al. 2014).

Fernandez-Gonzalez et al. (2015) reported the expected environmental benefits of replacing conventional energies with renewable energy resources such as wind or photovoltaic (PV) solar energy. PV solar energy is accepted as a technical and commercially mature technology. Herrero-Gonzalez et al. (2018a) states the feasibility at lab scale for the production of $\mathrm{HCl}$ and $\mathrm{NaOH}$ from desalination brines by means of EDBM powered by PV.

EDBM powered by PV solar energy is able to meet the above-mentioned challenges that arise in SWRO desalination: i) brine treatment and valorization, and ii) employment of renewable energy resources.

Considering the potential advantages of EDBM powered by PV, a methodological approach to address them appears to be necessary. Among available tools, Life Cycle Assessment (LCA) emerges as an excellent candidate to complete the evaluation of the associated environmental impacts. Indeed, from the early 2000s, there was an increase in studies published for drinking water production techniques. Most of the studies focused on the comparison between different methods of water treatment and desalination, while others focused on identifying "hot spots" in the multiple processes. Among the identified hot spots, highenergy consumption (Meneses et al. 2010; Shahabi et al. 2014; Cherchi et al. 2017; Aleisa and Al-Shayji 2018) and brine disposal issues (Meneses et al. 2010; Zhou et al. 2013, 2014) stand out. Other representative LCA studies are focused on the comparison of freshwater supply alternatives (Uche et al. 2015; Biswas and 
Yek 2016). Thus, the approach given by LCA will used for the assessment of the Carbon Footprint (CF) of the process.

In this sense, the aim of this present work is the study of the environmental sustainability of a novel EDBM brine treatment for the production of acids and bases integrated in a SWRO desalination plant, with special focus in the implications of the amount of brine to be treated. The study will be carried out from a life cycle perspective, focusing on the two SWRO main environmental drawbacks: brine disposal into the sea and indirect GHG emissions due to the high-energy consumption of the processes. To assess the brine disposal problem, the amount of brine released will be used as metric. CF will be calculated and employed as environmental metric related to the energy consumption. Four different scenarios will be analyzed based on the amount of brine sent to the brine treatment. In addition, a sensitivity analysis regarding the used electric power supply will be performed, creating three alternatives for each scenario.

\section{Methodology}

\subsection{System and Functional Unit description}

The integrated process consists of two main sections: SWRO and EDBM. Seawater and chemicals $(\mathrm{NaOH}$ and $\mathrm{HCl})$ are the two material inputs, also two energy inputs are considered. Six streams are considered as material outputs: freshwater, concentrated brine, $\mathrm{HCl}, \mathrm{NaOH}$ and treated brine. The produced $\mathrm{HCl}$ and $\mathrm{NaOH}$ can be employed for self-supply in both units. Since the produced $\mathrm{HCl}$ and $\mathrm{NaOH}$ solutions are at a higher concentration than the one required, they can be properly added according to the corresponding dosage. However, if the obtained products are expected to be commercialized, and distributed outside the facility, this in turn created another issue, as it will require concentration stages, which have been also considered. The described process flowsheet is represented in Fig. 1.

The SWRO desalination unit and the EDBM unit displayed the same features in every studied alternative, whereas the amount of brine treated within the EDBM unit varies in the different alternatives. Mainly, only operation stages are considered. In this sense, the use of chemicals and energy consumed are considered. However, stages such as construction and dismantling are neglected. Transportation is also not included in the boundaries. System boundaries are represented in Fig. 2.

The SWRO process includes the pre-treatment stage, high pressure pump, selective membrane, posttreatment and membrane cleaning. In the present work, a concentration of $31.7 \mathrm{~g} \cdot \mathrm{L}^{-1}$ has been considered as average seawater concentration which varies between 20 and $50 \mathrm{~g} \cdot \mathrm{L}^{-1}$ (Jones et al. 2019), while twice the concentration, $63.5 \mathrm{~g} \cdot \mathrm{L}^{-1}$ has been considered for the brine. According to previous works from the 
authors, the transformation of $\mathrm{NaCl}$ into $\mathrm{HCl}$ y $\mathrm{NaOH}$ is possible under proper experimental conditions at lab-scale. Results showed that $1.13 \mathrm{~mol} \cdot \mathrm{L}^{-1} \mathrm{HCl}$ and $\mathrm{NaOH}$ are produced in the EDBM process. In this work, the evaporation of water leads to a concentration $30 \%$ wt. $\mathrm{HCl}$ and $98 \%$ wt. $\mathrm{NaOH}$.

Spanish grid mix, Israeli grid mix and PV solar electric power supplies will be compared. Both countries, Spain and Israel, suffer water shortages; however, they both rely on desalination technology development. Nowadays, these two countries are SWRO technology exporters, holding positions in the worldwide top 10 ranking of countries by total installed desalination capacity, 3.8 million $\mathrm{m}^{3} \cdot \mathrm{day}^{-1}$ and 1.5 million $\mathrm{m}^{3} \cdot$ day $^{-1}$, respectively, with the expectation of additional growth in the coming years (IDA 2015). Additionally, solar irradiation conditions can be assumed similar for both countries (around 5.5 $\left.\mathrm{kWh} \cdot\left(\mathrm{m}^{2} \cdot \text { day }\right)^{-1}\right)($ PVGIS 2017).

The FU is defined as $1.0 \mathrm{~m}^{3}$ of freshwater produced in the desalination process. This FU would allow a direct comparison of the alternatives.

2.2. Grid mix composition and its corresponding carbon footprint

Table 1 reports the composition of the Spanish and the Israeli grid mix. Moreover, a single carbon footprint value is proposed (Herrero-Gonzalez et al. 2018b) for each energy source, due to the wide ranges of values reported by the literature, mainly represented by the IPPC directive (Schlömer et al. 2014).

Table 1. Spanish and Israeli grid mix share in 2015 (IEA 2016a). Carbon footprints for different selected electric energy sources (reported in Herrero-Gonzalez et al. (2018b)).

\begin{tabular}{|c|c|c|c|c|c|c|c|c|}
\hline \multirow{3}{*}{$\begin{array}{c}\text { Indicator } \\
\text { Electric energy } \\
\text { source }\end{array}$} & \multicolumn{2}{|c|}{ Grid mix share } & \multicolumn{6}{|c|}{ Carbon footprint $\left(\mathrm{kg} \mathrm{CO} 2-\mathrm{eq} \cdot \cdot \mathrm{GJ}^{-1}\right)$} \\
\hline & \multirow{2}{*}{$\begin{array}{l}\text { Spain } \\
(\%)\end{array}$} & \multirow{2}{*}{$\begin{array}{c}\text { Israel } \\
(\%)\end{array}$} & \multirow{2}{*}{$\begin{array}{l}\text { Herrero-Gonzalez } \\
\text { et al. (2018b) }\end{array}$} & \multicolumn{3}{|c|}{ Schlömer et al. (2014) } & \multirow{2}{*}{$\begin{array}{l}\text { Varun et al. } \\
\text { (2009) }\end{array}$} & \multirow{2}{*}{$\begin{array}{c}\text { Foro de la } \\
\text { Industria Nuclear } \\
\text { Española (2017) }\end{array}$} \\
\hline & & & & Min. & Med. & Max. & & \\
\hline Oil & 6.1 & 0.7 & 200 & & & & 206 & \\
\hline Coal & 18.7 & 45.8 & 250 & 205.6 & 227.8 & 252.8 & 228 & \\
\hline Nuclear & 20.4 & 0.0 & 5 & 1 & 3.3 & 30.6 & 3 & \\
\hline Hydro & 11.2 & 0.0 & 5 & 0.3 & 6.7 & 611.1 & 7 & \\
\hline Solar PV & 2.9 & 1.7 & 10 & 5 & 13.3 & 50.0 & 13 & \\
\hline
\end{tabular}




\begin{tabular}{|c|c|c|c|c|c|c|c|c|}
\hline Solar thermal & 2.0 & 0.0 & 10 & 2.4 & 7.5 & 17.5 & 8 & \\
\hline Wind & 17.6 & 0.0 & 5 & 1.9 & 3.1 & 15.6 & 3 & \\
\hline Tide & 0.0 & 0.0 & - & & & & & \\
\hline Other sources & 0.1 & 0.0 & - & & & & & \\
\hline $\begin{array}{c}\text { Global Carbon } \\
\text { Footprint (kg } \\
\mathbf{C O}_{2} \text {-eq. } \cdot \mathbf{G J}^{-1} \text { ) }\end{array}$ & 94 & 194 & & \multicolumn{7}{|l|}{} & & \\
\hline
\end{tabular}

${ }^{\mathrm{a}}$ Considered as biomass

\subsection{Selected Scenarios}

Four different scenarios were selected regarding the percentage of produced brine being treated by means of EDBM. In addition, three different electric power supplies will be analyzed: $100.0 \%$ renewable energy (PV solar energy), 36.0\% renewable energy (Spanish grid mix) and 1.9\% renewable energy (Israeli grid mix). A proper description of the scenarios is depicted in Table 2.

Table 2. Scenarios description.

\begin{tabular}{|l|r|r|r|r|}
\hline & \multicolumn{1}{|l|}{ Scenario 1 } & \multicolumn{1}{l|}{ Scenario 2 } & \multicolumn{1}{l|}{ Scenario 3 } & \multicolumn{1}{l|}{ Scenario 4 } \\
\hline Rate of Treated Brine (\%) & 0.0 & 1.8 & 50.0 & 100.0 \\
\hline $\begin{array}{l}\text { Discharge of Brine (\% } \\
\text { brine to seawater) }\end{array}$ & 100.0 & 98.2 & 50.0 & 0.0 \\
\hline HCl Self-supply Ratio (\%) & 0.0 & 100.0 & \multicolumn{1}{|c|}{100.0} & 100.0 \\
\hline Products for sale & Freshwater & Freshwater & $\begin{array}{l}\text { Freshwater, } \\
\mathrm{HCl}(30 \% \text { wt.) } \\
\text { and NaOH } \\
(98 \% \text { wt.) }\end{array}$ & $\begin{array}{l}\text { Freshwater, } \\
\mathrm{HCl}(30 \% \text { wt.) } \\
\text { and NaOH } \\
(98 \% \text { wt.) }\end{array}$ \\
\hline
\end{tabular}

Scenario 1, which does not consider EDBM brine treatment and freshwater as the only product, will be considered as reference. Scenarios 2, 3 and 4 consider EDBM brine treatment for the production of $\mathrm{HCl}$ and $\mathrm{NaOH}$, avoiding external reagents purchase. However, different volume of brine is treated. Only the reagents required for self-supply are produced in Scenario 2, this means $1.8 \%$ of brine treatment if the maximum dosage of $\mathrm{HCl}$ is considered. Whereas overproduction of reagents for sale in Scenarios 3 and 4 is proposed. Scenario 3 considers a brine treatment of a $50.0 \%$, while in Scenario 4 the total brine is treated. As summary, Scenario 1 represents a SWRO plant, Scenario 2 a SWRO with reagents self-supply, and finally, Scenarios 3 and 4 a SWRO plant plus a reagents production plant.

\subsection{Summary of assumptions and hypothesis}

The following assumptions and hypothesis have been considered in the LCA study:

a) Infrastructure (construction and dismantling) impacts have been neglected. 
b) Transportation of reagents (both to the plant and from the plant) has not been included in the system boundaries.

c) An aggregated consumption of electric power for SWRO of $3 \mathrm{~kW} \cdot \mathrm{h} \cdot \mathrm{m}^{-3}$ of seawater (SchallenbergRodríguez et al. 2014). Thus, considering a 50.0\% of freshwater production (Meneses et al. 2010) means 6 $\mathrm{kWh} \cdot \mathrm{m}^{-3}$ of freshwater has been considered. This includes: pre-treatment stage, high-pressure pump, selective membrane, post-treatment and membrane cleaning.

d) Concentration of brines has been considered as $63.5 \mathrm{~g} \cdot \mathrm{L}^{-1}$ of $\mathrm{NaCl}$ (Herrero-Gonzalez et al. 2018a).

e) Concentration of seawater has been considered as $31.7 \mathrm{~g} \cdot \mathrm{L}^{-1}$ of $\mathrm{NaCl}$ (Herrero-Gonzalez et al. 2018a).

f) SWRO produces equal quantities of freshwater and brines.

g) EDBM energy consumption at laboratory scale of $4.4 \mathrm{kWh} \cdot \mathrm{kg}^{-1} \mathrm{HCl}$ (Herrero-Gonzalez et al. 2018a) has been considered scalable to industrial set-up.

h) The heat requirements for the concentration stages of acid (35\% vol.) and base (dry product) are calculated through the latent heat of vaporization of water $\left(2,257 \mathrm{MJ} \cdot \operatorname{ton}^{-1}\right)$ to reach the desired purity. CF for the steam has been considered as $0.294 \mathrm{~kg} \cdot \mathrm{kWh}^{-1}$ (Wernet et al. 2016).

i) Density is rounded up to $1,000 \mathrm{~kg} \cdot \mathrm{m}^{-3}$.

\subsection{Life Cycle Inventory}

In order to provide the data for the LCI, mass and energy balances were performed for the four scenarios. Data from updated references has been considered for the elaboration of the inventory of the SWRO section. Data for the EDBM process is obtained from previous works of the research group (Herrero-Gonzalez et al. 2018a). All inputs and outputs for $1.0 \mathrm{~m}^{3}$ of freshwater for each scenario are summarized on Table 3.

Table 3. Inputs and outputs for $1 \mathrm{~m}^{3}$ of freshwater produced for each scenario.

\begin{tabular}{|l|r|r|r|r|l|l|l|}
\hline Component & Scenario 1 & Scenario 2 & Scenario 3 & Scenario 4 & Unit & Ref. \\
\hline Inputs & 2,300 & 2,319 & 2,399 & 2,489 & $\mathrm{~kg}$ & Own calculation \\
\hline Seawater & 0.146 & 0.146 & 0.146 & 0.146 & $\mathrm{~kg}$ & $\begin{array}{l}\text { Fernandez- } \\
\text { Gonzalez et al. } \\
2016\end{array}$ \\
\hline Chemicals \\
$\mathrm{HCl}$
\end{tabular}




\begin{tabular}{|c|c|c|c|c|c|c|}
\hline $\begin{array}{l}\text { acid and } \\
\text { base }\end{array}$ & & & & & & \\
\hline \multicolumn{7}{|l|}{ Outputs } \\
\hline \multicolumn{7}{|l|}{ Products } \\
\hline Freshwater & 1,000 & 1,000 & 1,000 & 1000 & $\mathrm{~kg}$ & Own calculation \\
\hline $\mathrm{HCl} 30 \% \mathrm{wt}$ & 0.0 & 0.4 & 41 & 86 & $\mathrm{~kg}$ & Own calculation \\
\hline $\begin{array}{l}\mathrm{NaOH} \\
98 \% \text { wt }\end{array}$ & 0.0 & 0.5 & 14 & 29 & $\mathrm{~kg}$ & Own calculation \\
\hline \multicolumn{7}{|l|}{ Waste } \\
\hline $\begin{array}{l}\text { Concentrate } \\
\mathrm{d} \text { Brine } 63.5 \\
\mathrm{~g} \cdot \mathrm{L}^{-1}\end{array}$ & 1,300 & 1,287 & 678 & 0 & $\mathrm{~kg}$ & Own calculation \\
\hline $\begin{array}{l}\text { Treated } \\
\text { brine } 31.8 \\
\mathrm{~g} \cdot \mathrm{L}^{-1}\end{array}$ & 0 & 23 & 658 & 1,365 & $\mathrm{~kg}$ & Own calculation \\
\hline
\end{tabular}

${ }^{\text {a }}$ The equivalence $3.6 \mathrm{MJ}=1 \mathrm{kWh}$ was employed in this work.

As it is clear from Table 3, both SWRO and EDBM require large amounts of energy as electricity. This fact is expected to result into energy production to be the main contributor to the environmental burdens, and, to the Carbon Footprint. Regarding the SWRO unit, the energy is employed for seawater pumping intake and for the high-pressure pump that generates the enough pressure gradient to allow water flux through the membrane; however, energy savings are achieved thanks to the energy recovery systems. On the other hand, energy in the EDBM unit is consumed in the generation of an electric potential difference that enables the flux of ions through the membranes. Brines are the main effluent generated during the process.

\subsection{Life Cycle Impact Assessment}

LCIA was carried out with Gabi 6 software (PE International 2014), which is linked to Ecoinvent database (Wernet et al. 2016) in order to obtain the environmental burdens associated to the individual processes. Climate Change (CC) has been chosen as main impact category due to the indirect emissions associated to the high-energy requirements of the studied processes. Hereafter, we use Carbon Footprint (CF) as reference for the burdens related to CC. Moreover, energy consumption has been previously reported as the desalination main environmental issue (Vince et al. 2008; Lyons et al. 2009; Meneses et al. 2010; Tarnacki et al. 2011, 2012; Al-Sarkal and Arafat 2013). In this way, the CF of each treated cubic meter of seawater treated can be assessed.

Large volumes of brines are disposed everyday into the sea, which not only generates an environmental burden but also an economic loss. Although no suitable characterization factor has been found in literature, Brine Discharge (BD) has been also considered, both amounts and concentrations, as not only the amount of volume causes the environmental impact on the media, also the variation in concentration. Consequently, 
it has been used a mid-point metric for the effect of the released brine into the vicinities of the facility. In this sense, all the released brines have a concentration between $31.8 \mathrm{~g} \cdot \mathrm{L}^{-1}$ of $\mathrm{NaCl}$ (full treated brine) and $63.5 \mathrm{~g} \cdot \mathrm{L}^{-1}$ of $\mathrm{NaCl}$ (direct disposal).

The environmental impact categories selected for this study are described in Table 4 .

Table 4 Selected environmental impact categories for the LCA.

\begin{tabular}{|l|l|l|l|}
\hline Impact Category & Method & Unit & Description \\
\hline Climate Change (CC) & IPCC equivalence factors & $\mathrm{kg} \mathrm{CO}$-eq. & $\begin{array}{l}\text { Amount of equivalent } \\
\text { emitted }\end{array}$ \\
\hline Brine discharge (BD) & Calculation (mass balance) & $\mathrm{kg}$ brine & $\begin{array}{l}\text { Amount of the brine discharge at } \\
\text { a concentration between } 31.8 \mathrm{~g} \cdot \mathrm{L}^{-} \\
1 \text { of } \mathrm{NaCl} \text { (full treated brine) and } \\
63.5 \mathrm{~g} \cdot \mathrm{L}^{-1} \text { of } \mathrm{NaCl}(\text { direct } \\
\text { disposal) }\end{array}$ \\
\hline
\end{tabular}

As the acid and the base products are obtained at low concentrations, additional concentration units were added, to those products that will be commercialized, in order to obtain the desired concentrations that allow their distribution, in this work $30 \%$ wt. and $98 \%$ wt. for $\mathrm{HCl}$ and $\mathrm{NaOH}$, respectively.

\section{Result and discussion}

\subsection{Life Cycle Interpretation}

Table 5 summarizes the results of BD calculated by mass balance for all four scenarios. Including brine valorization by means of EDBM has as result the light increase of the amount of brine generation, between $0.77 \%$ (Scenario 2 ) and $5.0 \%$ (Scenario 4 ), which is due to the slightly higher amounts of seawater required in order to produced $1.0 \mathrm{~m}^{3}$ of freshwater. SWRO brine mostly consists on a highly concentrated $\mathrm{NaCl}$ solution $\left(63.5 \mathrm{~g} \cdot \mathrm{L}^{-1}\right)$, yet some residual chemicals from pre-treatment stages are estimated to be potentially found. After EDBM, $\mathrm{NaCl}$ concentration in the brines is halved $\left(31.8 \mathrm{~g} \cdot \mathrm{L}^{-1}\right)$, thus, depending on the percentage of brine sent to EDBM treatment, total brine discharge average concentrations in a range between $31.8 \mathrm{~g} \cdot \mathrm{L}^{-1}$ and $63.5 \mathrm{~g} \cdot \mathrm{L}^{-1}$ can be obtained $(100.0 \%$ and $1.8 \%$ treated brine respectively). The greater the amount of concentrated brine treated by means EDBM, the lower the average concertation of the total brine discharged. The minimum discharge concentration $\left(31.8 \mathrm{~g} \cdot \mathrm{L}^{-1}\right)$ is obtained for Scenario 4 , where all the brine is treated. In addition, treating less than $1.8 \%$ of the brine will not be enough for self-supplying requirements. 
Table 5. Mass balance results including brine discharge per $1 \mathrm{~m}^{3}$ of freshwater

\begin{tabular}{|l|r|r|r|r|r|}
\hline & $\begin{array}{l}\text { Rate of } \\
\text { treated } \\
\text { brine }\end{array}$ & $\begin{array}{l}\text { Concentrated } \\
\text { brine discharge } \\
\left(\mathbf{6 3 . 5 1} \mathbf{g} \cdot \mathbf{L}^{-1}\right)\end{array}$ & $\begin{array}{l}\text { Treated brine } \\
\text { discharge } \\
\left(\mathbf{3 1 . 7 5} \mathbf{~ g} \cdot \mathbf{L}^{-1}\right)\end{array}$ & $\begin{array}{l}\text { Total brine } \\
\text { discharge }\end{array}$ & $\begin{array}{l}\text { Total brine } \\
\text { discharge average } \\
\text { concentration }\end{array}$ \\
\hline Units & $\mathbf{~}$ & $\mathbf{k g}$ & $\mathbf{k g}$ & $\mathbf{k g}$ & $\mathbf{g} \cdot \mathbf{L}^{\mathbf{- 1}}$ \\
\hline Scenario 1 & 0.0 & 1300 & 23 & 1310 & 63.51 \\
\hline Scenario 2 & 1.8 & 1287 & 658 & 1336 & 47.87 \\
\hline Scenario 3 & 50.0 & 678 & 1365 & 1365 & 31.75 \\
\hline Scenario 4 & 100.0 & 0.0 & & & 62.95 \\
\hline
\end{tabular}

The environmental performance regarding the selected categories, $\mathrm{CC}$ (as $\mathrm{kg} \cdot \mathrm{m}^{-3}$ ) and $\mathrm{BD}$, corresponding to each electric power supply Spanish and Israeli grid mixes and PV solar energy are presented on Fig. 3.

Dashtpour and Al-Zubaidy (2012) reported SWRO energy consumptions between $3.0 \mathrm{kWh} \cdot \mathrm{m}^{-3}$ and $10.0 \mathrm{kWh} \cdot \mathrm{m}^{-3}$ of seawater. For example, Las Palmas III-IV SWRO desalination plant (located in Spain) presents an energy consumption of $3.0 \mathrm{kWh} \cdot \mathrm{m}^{-3}$ (Schallenberg-Rodríguez et al. 2014). Taking into account the grid mix composition for Spain and Israel in 2015 reported by IEA (IEA 2016b) and the CF for different energy sources published in the IPPC directive (Schlömer et al. 2014), CF of $10 \mathrm{~kg} \mathrm{CO}$-eq· GJ ${ }^{-1}, 194 \mathrm{~kg}$ $\mathrm{CO}_{2}$-eq $\cdot \mathrm{GJ}^{-1}$ and $94 \mathrm{~kg} \mathrm{CO}$-eq $\cdot \mathrm{GJ}^{-1}$ for $\mathrm{PV}$ solar energy, Israeli grid mix and Spanish grid mix, respectively, have been calculated. The CF obtained in this work for SWRO and self-supply (Scenario 2) reagent production by means of EDBM for Spanish grid mix, Israeli grid mix and PV solar energy are 6.96 $\mathrm{kg} \mathrm{CO}$-eq. $\cdot \mathrm{m}^{-3}$ of freshwater, $12.57 \mathrm{~kg} \mathrm{CO}$-eq. $\cdot \mathrm{m}^{-3}$ of freshwater, and $2.17 \mathrm{~kg} \mathrm{CO}_{2}$-eq. $\cdot \mathrm{m}^{-3}$ of freshwater, respectively. In general, as the amount of brine treated by the EDBM increases, the CF increases as well, for the three electric power supplies studied. In addition, for every scenario, the Israeli grid mix has the largest CF, followed by the Spanish grid mix and the lowest CF is for PV solar energy. The CF decreases as the contribution of renewable energy sources increases in the electric power supply $(1.9 \%, 36.0 \%$ and $100 \%$ for the Israeli grid mix, the Spanish grid mix and the PV solar energy, respectively). The selection of PV solar energy as electric power supply mean reductions of $68.8 \%$ and $82.7 \%$ in the $\mathrm{CF}$, in the case of Spain and Israel. Moreover, the main contributors to the $\mathrm{CF}$ are the $\mathrm{HCl}$ and $\mathrm{NaOH}$ concentration stages, which are highly intensive in steam consumption.

A comparison of the production capacity and the associated CF for each electric power supply and scenario is reported in Fig. 4. Another aspect that should be considered in the calculation of the CF is the number of products produced. $\mathrm{As} \mathrm{HCl}$ and $\mathrm{NaOH}$ capacity is increased, more seawater is required in order to produce $1.0 \mathrm{~m}^{3}$ of freshwater. This is a result of the freshwater consumption by the EDBM to support 
the acid and the base streams. In Scenario 4, the only environmental impact is the emission of GHG contributing to the $\mathrm{CF}$, as the released brine has the same concentration as seawater thus no damage on the environment is foreseen.

Fig. 5 depicts the contribution of each step analyzed to the overall carbon footprint of the process. The percentage of each step is independent of the grid mix employed; otherwise, it is dependent on the scenario. As the percentage of treated brine is increased (scenarios 2 to 4), the contribution of the EDBM and concentration stages increases and becomes more relevant, making the SWRO less than 5\% for scenarios 3 and 4. It can also be observed that the most energy-intensive stage, and therefore the one that contributes the most to $\mathrm{CF}$, is the concentration stage. Even if the percentage of brine treated is minimum (1.8\% for scenario 2), the contribution of the concentration of products to the CF is greater than $35 \%$, and for scenarios 3 and 4 greater than $80 \%$.

Therefore, once both the $\mathrm{BD}$ and the $\mathrm{CF}$ are analyzed, the scenario that should be selected for operation could be determined. In this sense, Fig. 6 compares both $\mathrm{BD}$ and $\mathrm{CF}$ indicators for the existing four scenarios. The reduction in the $\mathrm{BD}$ indicator is intrinsically tied to an increase in $\mathrm{CF}$ due to the use of energy for the products concentration, so a compromise must be reached between these conflicting goals. Scenarios 3 and 4 compromise seriously the environmental sustainability of the integrated as the associated CF per unit of volume of freshwater is too high compared to the one obtained in Scenario 1. As a result, the authors consider that the trade-off depicted by Scenario 2 could be the preferred option, since the increase in CF is moderate in comparison with scenarios 3 and 4 . However, this configuration would not be enough to avoid the environmental burdens associated with brines disposal, so that the system studied should be coupled with other zero liquid discharge systems. The whole process can be environmentally improved with an increase in the concentration of products at the EDBM stage due to the reduction in the energy consumption of the concentration stage. This way, a higher volume of brines could be treated without such a high increment on the CF, especially when PV solar energy is considered.

\section{Conclusions}

The integration of EDBM with SWRO process influences the two main environmental burdens of SWRO desalination process: carbon footprint, associated to the indirect GHG emissions from to the highenergy consumption of electric power when the grid mix is not dominated by renewables; and the environmental alteration of the vicinities of the facility, due to brine disposal.

EDBM can significantly decrease the environmental burdens caused by SWRO desalination brine discharge, solving both amount and concentration (a concentration drop to $31.7 \mathrm{~g} \cdot \mathrm{L}^{-1}$ from $63.5 \mathrm{~g} \cdot \mathrm{L}^{-1}$, as a function of the amount of treated brine). Concentrations of $31.7 \mathrm{~g} \cdot \mathrm{L}^{-1}$ for the treated brine, similar to seawater, are achieved, and therefore, brine disposal into the sea could be executed without, or at least very 
low harm to the aquatic media. The percentage of treated brines ranging from $1.8 \%$ to $100 \%$ is considered in the different scenarios. The lowest value (1.8\%) within the range means the self-supply of the SWRO regarding $\mathrm{HCl}$ and $\mathrm{NaOH}$ (considering the technical maximum $\mathrm{HCl}$ dosage).

The integration of EDBM with SWRO process largely increased the demand of thermal energy for the concentration of the products, thus the corresponding CF. The benefits come from avoiding the need of purchasing external chemical that can be produced in-situ. However, these environmental credits are not enough to compensate the burdens derived for the steam consumption. The CF obtained in this work for SWRO and self-supply reagent production (scenario 2) by means of EDBM for Spanish grid mix, Israeli grid mix and PV solar energy are $6.96 \mathrm{~kg} \mathrm{CO}-\mathrm{eq} \cdot \mathrm{m}^{-3}$ of freshwater, $12.57 \mathrm{~kg} \mathrm{CO}$-eq $\cdot \mathrm{m}^{-3}$ of freshwater, and $2.17 \mathrm{~kg} \mathrm{CO}$-eq $\cdot \mathrm{m}^{-3}$ of freshwater, respectively. Reductions of $68.8 \%$ and $82.7 \%$ in $\mathrm{CF}$ can be achieved if renewable energy sources are employed instead of Spanish and Israeli grid mixes, respectively. Moreover, operating the novel integrated process with PV solar energy will be translated into an improved CF performance. In addition, product concentration stages have been identified as the major contributor to the overall CF of the SWRO with EDBM brine treatment integrated process.

This work contributes to assist in the assessment of the environmental impact of the novel integration of EDBM within the SWRO process for desalination brines valorization. Further work in the performance of a comprehensive LCA with all impact categories usually applied in wastewater management for wider understanding of the impacts caused is recommended.

\section{Acknowledgements}

Financial support from MICINN under project CTM2014-57833-R is gratefully acknowledged. Marta Herrero-Gonzalez thanks the MICINN for FPI grant BES-2015-07350. Marta Herrero and Noy Admon thank the Erasmus+ program for the Student Mobility KA107 grant.

\section{Abbreviations}

$\begin{array}{ll}\text { BD } & \text { Brine Discharge } \\ \text { CC } & \text { Climate Change } \\ \text { CF } & \text { Carbon Footprint } \\ \text { FU } & \text { Functional Unit } \\ \text { GHG } & \text { Greenhouse Gas } \\ \text { LCA } & \text { Life Cycle Assessment } \\ \text { PV } & \text { Photovoltaic } \\ \text { SWRO } & \text { Seawater Reverse Osmosis }\end{array}$

\section{References}

Al-Sarkal T, Arafat HA (2013) Ultrafiltration versus sedimentation-based pretreatment in Fujairah-1 RO 
plant: Environmental impact study. Desalination 317:55-66. doi: 10.1016/j.desal.2013.02.019

Aleisa E, Al-Shayji K (2018) Ecological-economic modeling to optimize a desalination policy: Case study of an arid rentier state. Desalination 430:64-73. doi: https://doi.org/10.1016/j.desal.2017.12.049

Amy G, Ghaffour N, Li ZY, et al (2017) Membrane-based seawater desalination: Present and future prospects. Desalination 401:16-21. doi: 10.1016/j.desa1.2016.10.002

Belkin N, Rahav E, Elifantz H, et al (2015) Enhanced salinities, as a proxy of seawater desalination discharges, impact coastal microbial communities of the eastern Mediterranean Sea. Environ Microbiol 17:4105-4120. doi: 10.1111/1462-2920.12979

Belkin N, Rahav E, Elifantz H, et al (2017) The effect of coagulants and antiscalants discharged with seawater desalination brines on coastal microbial communities: A laboratory and in situ study from the southeastern Mediterranean. Water Res 110:321-331. doi: 10.1016/j.watres.2016.12.013

Biswas WK, Yek P (2016) Improving the carbon footprint of water treatment with renewable energy: a Western Australian case study. Renewables Wind Water, Sol 3:14. doi: 10.1186/s40807-016-0036-2

Cherchi C, Badruzzaman M, Becker L, Jacangelo JG (2017) Natural gas and grid electricity for seawater desalination: An economic and environmental life-cycle comparison. Desalination 414:89-97. doi: 10.1016/j.desal.2017.03.028

Dashtpour R, Al-Zubaidy SN (2012) Energy Efficient Reverse Osmosis Desalination Process. Int J Environ Sci Dev 3:339-345.

de-la-Ossa-Carretero JA, Del-Pilar-Ruso Y, Loya-Fernández A, et al (2016) Bioindicators as metrics for environmental monitoring of desalination plant discharges. Mar Pollut Bull 103:313-318. doi: 10.1016/j.marpolbul.2015.12.023

Del-Pilar-Ruso Y, De-la-Ossa-Carretero JA, Giménez-Casalduero F, Sánchez-Lizaso JL (2008) Effects of a brine discharge over soft bottom Polychaeta assemblage. Environ Pollut 156:240-250. doi: 10.1016/j.envpol.2007.12.041

Drioli E, Ali A, Macedonio F (2017) Membrane Operations for Process Intensification in Desalination. Appl Sci 7:100. doi: 10.3390/app7010100

Einav R, Harussi K, Perry D (2003) The footprint of the desalination processes on the environment. Desalination 152:141-154. doi: 10.1016/S0011-9164(02)01057-3

Fernandez-Gonzalez C, Dominguez-Ramos A, Ibañez R, Irabien A (2015) Sustainability assessment of electrodialysis powered by photovoltaic solar energy for freshwater production. Renew Sustain Energy Rev 47:604-615. doi: 10.1016/j.rser.2015.03.018

Fernandez-Gonzalez C, Dominguez-Ramos A, Ibañez R, Irabien A (2016) Electrodialysis with Bipolar Membranes for Valorization of Brines. Sep Purif Rev 45:275-287. doi: $10.1080 / 15422119.2015 .1128951$

Fernández-Torquemada Y, Sánchez-Lizaso JL (2005) Effects of salinity on leaf growth and survival of the Mediterranean seagrass Posidonia oceanica (L.) Delile. J Exp Mar Bio Ecol 320:57-63. doi: 10.1016/j.jembe.2004.12.019

Foro de la Industria Nuclear Española (2017) Energía 2017. 
Gacia E, Invers O, Manzanera M, et al (2007) Impact of the brine from a desalination plant on a shallow seagrass (Posidonia oceanica) meadow. Estuar Coast Shelf Sci 72:579-590. doi: 10.1016/j.ecss.2006.11.021

García-Rubio MA, Guardiola J (2012) Desalination in Spain: A growing alternative for water supply. Int J Water Resour Dev 28:171-186. doi: 10.1080/07900627.2012.642245

Herrero-Gonzalez M, Diaz-Guridi P, Dominguez-Ramos A, et al (2018a) Photovoltaic solar electrodialysis with bipolar membranes. Desalination 433:155-163. doi: https:// doi.org/10.1016/j.desal.2018.01.015

Herrero-Gonzalez M, Wolfson A, Dominguez-Ramos A, et al (2018b) Monetizing Environmental Footprints: Index Development and Application to a Solar-Powered Chemicals Self-Supplied Desalination Plant. Sustain Chem Eng 6:14533-14541. doi: 10.1021/acssuschemeng.8b03161

IDA (2014) Desalination by the Numbers | IDA. In: Int. Desalin. Assoc. http://idadesal.org/desalination101/desalination-by-the-numbers/. Accessed 4 Jun 2017

IDA (2015) Water Desalination Report.

IEA (2016a) Key World Energy Statistics 2016.

IEA (2016b) International Energy Agency. http://www.iea.org/. Accessed 13 Jul 2017

Jiang C, Wang Y, Wang Q, et al (2014a) Production of lithium hydroxide from lake brines through electroelectrodialysis with bipolar membranes (EEDBM). Ind Eng Chem Res 53:6103-6112. doi: 10.1021/ie404334s

Jiang C, Wang Y, Zhang Z, Xu T (2014b) Electrodialysis of concentrated brine from RO plant to produce coarse salt and freshwater. J Memb Sci 450:323-330. doi: 10.1016/j.memsci.2013.09.020

Jones E, Qadir M, Vliet MTH Van, et al (2019) The state of desalination and brine production : A global outlook. Sci Total Environ 657:1343-1356. doi: 10.1016/j.scitotenv.2018.12.076

Kalogirou SA (2001) Effect of fuel cost on the price of desalination water: A case for renewables. Desalination 138:137-144. doi: 10.1016/S0011-9164(01)00255-7

Koter S, Warszawski A (2006) A new model for characterization of bipolar membrane electrodialysis of brine. Desalination 198:111-123. doi: 10.1016/j.desal.2006.09.016

Lyons E, Zhang P, Benn T, et al (2009) Life cycle assessment of three water supply systems: Importation, reclamation and desalination. Water Sci Technol Water Supply 9:439-448. doi: 10.2166/ws.2009.534

Masdar (2015) Global CO2 Emissions of Water Desalination Plants.

Meneses M, Pasqualino JC, Céspedes-Sánchez R, Castells F (2010) Alternatives for reducing the environmental impact of the main residue from a desalination plant. J Ind Ecol 14:512-527. doi: $10.1111 / \mathrm{j} .1530-9290.2010 .00225 . \mathrm{x}$

Ortiz-Albo P, Ibañez R, Urtiaga A, Ortiz I (2019) Phenomenological prediction of desalination brines nanofiltration through the indirect determination of zeta potential. Sep Purif Technol. doi: 10.1016/j.seppur.2018.08.066

Palomar P, Losada IJ (2011) CHAPTER : THE IMPACTS OF DESALINATION ON THE MARINE. In: The Marine Environment: Ecology, Management and Conservation. 
PE International (2014) GaBi 6 Software and Databases for Life Cycle Assessment.

Pérez-González A, Urtiaga AM, Ibáñez R, Ortiz I (2012) State of the art and review on the treatment technologies of water reverse osmosis concentrates. Water Res 46:267-283. doi: 10.1016/j.watres.2011.10.046

PVGIS (2017) JRC's Directorate C: Energy, Transport and Climate - PVGIS - European Commission. http://re.jrc.ec.europa.eu/pvgis/. Accessed 21 Apr 2017

Ras C, von Blottnitz H (2012) A comparative life cycle assessment of process water treatment technologies at the Secunda industrial complex, South Africa. Water SA 38:549-554. doi: http://dx.doi.org/10.4314/wsa.v38i4.10

Reig M, Valderrama C, Gibert O, Cortina JL (2016) Selectrodialysis and bipolar membrane electrodialysis combination for industrial process brines treatment: Monovalent-divalent ions separation and acid and base production. Desalination 399:88-95. doi: 10.1016/j.desal.2016.08.010

Roberts DA, Johnston EL, Knott NA (2010) Impacts of desalination plant discharges on the marine environment: A critical review of published studies. Water Res 44:5117-5128. doi: 10.1016/j.watres.2010.04.036

Röthig T, Ochsenkühn MA, Roik A, et al (2016) Long-term salinity tolerance is accompanied by major restructuring of the coral bacterial microbiome. Mol Ecol 25:1308-1323. doi: 10.1111/mec.13567

Sánchez-Lizaso JL, Romero J, Ruiz J, et al (2008) Salinity tolerance of the Mediterranean seagrass Posidonia oceanica: recommendations to minimize the impact of brine discharges from desalination plants. Desalination 221:602-607. doi: 10.1016/j.desal.2007.01.119

Schallenberg-Rodríguez J, Veza JM, Blanco-Marigorta A (2014) Energy efficiency and desalination in the Canary Islands. Renew Sustain Energy Rev 40:741-748. doi: 10.1016/j.rser.2014.07.213

Schlömer S, Bruckner T, Fulton L, et al (2014) Annex III: Technology-specific cost and performance parameters. In: Edenhofer O, Pichs-Madruga R, Sokona Y, et al. (eds) Climate Change 2014: Mitigation of Climate Change. Contribution of Working Group III to the Fifth Assessment Report of the Intergovernmental Panel on Climate Change. Cambridge University Press, Cambridge, United Kingdom and New York, NY, USA.,

Shahabi MP, McHugh A, Anda M, Ho G (2014) Environmental life cycle assessment of seawater reverse osmosis desalination plant powered by renewable energy. Renew Energy 67:53-58. doi: 10.1016/j.renene.2013.11.050

Shahzad MW, Burhan M, Ang L, Ng KC (2017) Energy-water-environment nexus underpinning future desalination sustainability. Desalination 413:52-64. doi: 10.1016/j.desal.2017.03.009

Tarnacki K, Meneses M, Melin T, et al (2012) Environmental assessment of desalination processes: Reverse osmosis and Memstill®. Desalination 296:69-80. doi: 10.1016/j.desal.2012.04.009

Tarnacki KM, Melin T, Jansen AE, Van Medevoort J (2011) Comparison of environmental impact and energy efficiency of desalination processes by LCA. Water Sci Technol Water Supply 11:246-251. doi: $10.2166 /$ ws.2011.052

Tate J (2008) Industrial Reverse Osmosis System Design. Water Cond Purif Mag 7:3. 
Uche J, Martínez-Gracia A, Círez F, Carmona U (2015) Environmental impact of water supply and water use in a Mediterranean water stressed region. J Clean Prod 88:196-204. doi: 10.1016/j.jclepro.2014.04.076

Varun, Bhat IK, Prakash R (2009) LCA of renewable energy for electricity generation systems-A review. Renew Sustain Energy Rev 13:1067-1073. doi: 10.1016/j.rser.2008.08.004

Vince F, Aoustin E, Bréant P, Marechal F (2008) LCA tool for the environmental evaluation of potable water production. Desalination 220:37-56. doi: 10.1016/j.desal.2007.01.021

Wang M, Wang KK, Jian YX, Ren QC (2014) The reclamation of brine generated from desalination process by bipolar membrane electrodialysis. J Memb Sci 452:54-61. doi: 10.1016/j.memsci.2013.10.029

Wernet G, Bauer C, Steubing B, et al (2016) The ecoinvent database version 3 (part I): overview and methodology. Int J Life Cycle Assess 21:1218-1230. doi: 10.1007/s11367-016-1087-8

Yang Y, Gao X, Fan A, et al (2014) An innovative beneficial reuse of seawater concentrate using bipolar membrane electrodialysis. J Memb Sci 449:119-126. doi: 10.1016/j.memsci.2013.07.066

Yoon SJ, Park GS (2011) Ecotoxicological effects of brine discharge on marine community by seawater desalination. Desalin Water Treat 33:240-247. doi: 10.5004/dwt.2011.2644

Zhou J, Chang VWC, Fane AG (2013) An improved life cycle impact assessment (LCIA) approach for assessing aquatic eco-toxic impact of brine disposal from seawater desalination plants. Desalination 308:233-241. doi: 10.1016/j.desal.2012.07.039

Zhou J, Chang VWC, Fane AG (2014) Life Cycle Assessment for desalination: A review on methodology feasibility and reliability. Water Res 61:210-223. doi: 10.1016/j.watres.2014.05.017

\section{Figure Captions}

Fig. 1 Process flowsheet.

Fig. 2 System boundaries $(\mathrm{HCl}$ and $\mathrm{NaOH}$ recirculation to EDBM has not been represented in order to simplify).

Fig. $3 \mathrm{CC}$ and $\mathrm{BD}$ for $1 \mathrm{~m}^{3}$ of freshwater for Spanish and Israeli grid mixes and PV solar energy.

Fig. 4 Production of $\mathrm{HCl}(30 \% \mathrm{wt})$ and $\mathrm{NaOH}(98 \% \mathrm{wt})$ vs GWP for Spanish and Israeli grid mixes and PV solar energy for $1 \mathrm{~m}^{3}$ of freshwater.

Fig. 5 Relative contribution of the SWRO, EDBM and the concentration stages to the overall carbon footprint.

Fig. 6 Summary of CF and BD for the four scenarios and energy sources studied. 